\title{
SICs e ouvidorias: uma análise das estruturas dos serviços de acesso à informação nas capitais brasileiras
}

SICs and ombudsmen: an analysis of structures of access to information services in Brazilian capitals

\section{Manuella Soares Ramalho ${ }^{1}$ Ana Carla Bliacheriene ${ }^{2}$}

\section{RESUMO}

A Lei de Acesso à Informação é um dos maiores marcos na busca da transparência no século 21 e se mostrou como um grande desafio para a Administração Pública. Este artigo visa apresentar um diagnóstico sobre as estruturas dos chamados Serviços de Informações ao Cidadão (SIC) nas 26 capitais dos estados brasileiros, e a utilização das estruturas existentes das ouvidorias para a implementação da transparência passiva nestes entes subnacionais, com a análise normativa e por meio de entrevistas com os responsáveis pelos SICs.

Palavras-chave: LAI. Serviços de Informações ao Cidadão. Ouvidoria. Transparência passiva.

\section{ABSTRACT}

The Access to Public Information Law is one of the greatest milestones in the search for transparency in the 21 st century and has proved to be a great challenge for Public Administration. This paper aims at presenting a diag-

\footnotetext{
1 Manuella Soares Ramalho - graduada em Direito pela UFPB, mestre em Gestão de Políticas Públicas pela USP, servidora pública do estado de São Paulo, onde atua na área de transparência, acesso à informação e controle social. E- mail: manuella_ramalho@yahoo.com.br.

2 Ana Carla Bliacheriene - professora da USP, advogada, mestre e doutora em Direito pela PUC-SP, livre-docente em direito pela USP, autora de livros e artigos sobre o controle interno. E- mail: acb@usp.br.
} 
nosis on the structures of the so-called Citizen Information Services (SIC) in the 26 capitals of the Brazilian states, and the use of existing structures of the ombudsmen for the implementation of passive transparency in these subnational entities, with normative analysis and through interviews with those responsible for SICs.

Keywords: LAI. Citizen Information Services. Ombudsman. Passive transparency.

Recebido: 04-02-2021

Aprovado: 23-04-2021

\section{INTRODUÇÃO}

A Lei de Acesso à Informação (LAI) - Lei n ${ }^{\circ}$ 12.527/2011 foi publicada para regulamentar o previsto na Constituição Federal (art. 5', XXXIII; art. $37, \S 3^{\circ}$, II; art. $216, \S 2^{\circ}$ ) e, assim, atender à demanda nacional e internacional de transparência e disponibilização de acesso à informação.

A referida lei brasileira é considerada uma das mais completas normas sobre o assunto, em comparação com a demais leis aprovadas pelo mundo, por abranger todas as esferas de Poder e entes federativos, além das empresas estatais. Nesse sentido, também é uma das mais ambiciosas (ANGELICO, 2012), pois faz parte de uma política de transparência e acesso à informação que não se esgota com a publicação da normativa, mas requer um empenho institucional de mudança de paradigmas da ação estatal e dos servidores, do sigilo à transparência da informação, em todos os níveis da federação.

Diversos estudos (ANGELICO, 2012; ARRUDA, 2016; MICHENER et al., 2018) apontaram como sendo uma das dificuldades na implementação dessa lei o aspecto federativo do país, no qual os entes subnacionais são autônomos administrativamente, mas não detêm capacidade 
financeira e de pessoal para a garantia de acesso do cidadão aos dados, mesmo quando obrigados pela lei. A mera formulação e previsão legal dessa política pública não asseguram o efetivo acesso à informação, por parte do cidadão. A correta implementação, como sendo uma das fases do seu ciclo, é necessária.

A política pública de transparência e acesso à informação, normatizada via Lei $n^{\circ} 12.527 / 2011$, traz uma importante contribuição para a análise da coordenação federativa, pois, mesmo com a descentralização do Estado por meio de entes políticos autônomos, as competências normativas e materiais encontram-se compartilhadas e, para que as políticas públicas tenham sucesso, são necessárias a integração e cooperação desses entes. Cabe à União encabeçar a coordenação das políticas, devido às competências previstas na Constituição Federal, concentração orçamentária e o melhor aparelhamento da máquina administrativa, além da cobrança internacional no caso de políticas públicas decorrentes de acordos internacionais, como é a política de transparência e acesso à informação. A concentração de competências no governo federal caracteriza a relação federativa na gestão da política, cabendo à União o papel de principal financiador, normatizador e coordenador das relações intergovernamentais (ARRETCHE, 2006).

Fernando Abrucio (2002) aponta que, para garantir essa coordenação entre níveis de governo, tem de haver equilíbrio das formas de cooperação e competição. A competição entre os entes pode estimular a superação com as inovações na gestão. Já a cooperação pode otimizar a utilização de recursos comuns, além de procurar a simetria entre os entes territoriais. Não se pode confundir com verticalização ou subordinação, mas como um apoio entre os entes que têm mais condição financeira e técnica, àqueles com recursos mais escassos. Também não se pode confundir com uniformização de políticas, que pode levar a uma diminuição da inovação em níveis subnacionais, enfraquecimento do controle de checks and balances intergovernamentais e dificuldade de responsabilização 
da Administração Pública. Já a competição não pode se tornar desmedida para não desencadear uma piora na questão redistributiva, sendo grande o desafio de encontrar um bom termo entre a cooperação e a competição. A implementação da Lei de Acesso à Informação é um exemplo da necessidade dessa cooperação federativa para que os entes subnacionais tenham sucesso na implementação da política pública nacional de transparência e acesso à informação.

A norma nacional precisou ser regulamentada nos níveis subnacionais, e estes têm a autonomia e competência material para sua implementação. Porém, o governo federal, por meio da Controladoria Geral da União (CGU), criou um programa de auxílio aos entes federados (Programa Brasil Transparente - Portaria CGU 277/2013), disponibilizando diversos instrumentos para implementação local da Lei de Acesso à Informação, além da conscientização sobre a necessidade da implantação da uma política de acesso às informações, para promover a mudança das práticas enraizadas do sigilo para a transparência.

Um dos aspectos apontados pelos estudos organizados por Michener (2016) sobre a LAI, para aferir se sua implementação foi eficiente, é o da estrutura utilizada para sua implementação, em especial a estrutura dos órgãos responsáveis pela chamada transparência passiva, materializada pelos SICs.

A LAI trouxe dois aspectos sobre a forma de disponibilização das informações: a transparência ativa e a transparência passiva. A transparência ativa é a que o Poder Público disponibiliza, independentemente de demanda específica do cidadão, ou por obrigação legal, ou por boas práticas da Administração Pública em seus portais na internet. São informações que despertam um interesse geral da população e são publicadas com certa periodicidade, legal ou não, fazendo parte da rotina de transparência do Estado.

Já a transparência passiva é a que o Estado fornece por demanda específica da sociedade, em pedidos individualizados e sem necessidade 
de motivação. Para atender a esse aspecto da transparência, a lei previu a criação dos Serviços de Informações ao Cidadão, em que o interessado realiza o pedido e o Estado internamente localiza a informação para disponibilizar, no prazo estabelecido na lei.

Conforme as diretrizes emanadas pela Controladoria Geral da União (2013), para se atender ao prazo previsto na LAI é importante que haja estrutura organizacional compatível, com atribuições claras. É igualmente recomendado que haja um sistema eletrônico para atender aos prazos legais e facilitar o encaminhamento da demanda internamente. Ademais, os atores envolvidos no processo de atendimento à demanda do cidadão devem ser capazes de localizar, analisar e classificar a informação, resguardando-se o sigilo legal, ou outra restrição de acesso, ou, ainda, se é informação pessoal e, sendo pública, fornecê-la da melhor forma. Isso tudo em um contexto de mudança de paradigma de não mais aceitar que a informação é exclusivamente interna e de que seu acesso é franqueado exclusivamente aos servidores públicos.

O objetivo deste artigo é apresentar um diagnóstico sobre as estruturas dos chamados Serviços de Informações ao Cidadão (SIC), nas 26 capitais dos estados brasileiros, e a utilização das estruturas existentes das ouvidorias para a implementação da transparência passiva.

A metodologia adotada na pesquisa foi a qualitativa, com a aplicação de entrevista semiestruturada, cujo foco das questões foi a observação das estruturas organizacionais adotadas para a implementação do SIC, de onde se pôde colher relatos de alguns atores que implementaram a política nas capitais sobre a estrutura e influência da orientação federal e utilização de estruturas preexistentes, como as ouvidorias.

As entrevistas foram realizadas com agentes públicos de sete capitais (São Paulo, Rio de Janeiro, Salvador, Fortaleza, Belo Horizonte), sendo as cinco maiores capitais em número de habitantes (IBGE, 2010), e duas (Porto Velho e Campo Grande) que tinham nota máxima na avaliação Escala Brasil Transparente da CGU, e que tinham aderido ao Programa 
Brasil Transparente da CGU, além de não terem previsão normativa de que a ouvidoria estivesse no fluxo do pedido de acesso à informação.

O corpus documental deste artigo sobre Lei de Acesso à Informação nas capitais foi construído por meio de perguntas nos SICs e pesquisa nos portais das Prefeituras, das 26 capitais, entre os meses de agosto e outubro de 2018. As normas analisadas estão atualizadas até janeiro de 2020. A análise documental acolheu e analisou: i) normas regulamentadoras sobre a Lei de Acesso à Informação; ii) as avaliações realizadas pela Fundação Getúlio Vargas (FGV) e a Escala Brasil Transparente da CGU, sobre os SICs; iii) normativas federais sobre a Lei de Acesso à Informação; iv) documentos sobre o Programa Brasil Transparente e adesão das capitais ao programa.

\section{TRANSPARÊNCIA E ACESSO À INFORMAÇÃO}

A transparência pública é um conceito construído ao longo do tempo. Na Constituição Federal de 1988, a previsão do princípio da publicidade dos atos administrativos (caput do art. $37^{4}$ ) era originalmente atendida pela publicação dos principais atos e de sua execução orçamentária nos Diários Oficiais dos entes federados ou em jornais de grande circulação. E embora este não fosse o único modo de publicização de informações de interesse público, ressalve-se que a possibilidade de acesso a certidões em cartórios públicos e demais demandas pessoais perante órgãos públicos, deviam ser precedidas pelo legítimo interesse pessoal, que desembocava invariavelmente no dever de motivação do peticionário. A Lei de Acesso à Informação quebra essa lógica ao desobrigar qualquer interessado de motivar o pedido de informação.

Na era da informação, as novas tecnologias migraram a informação da plataforma física impressa para os meios digitais. A Administração Pú-

\footnotetext{
$3 \quad$ MICHENER, 2016.

4 Constituição Federal de 1998: “Art. 37. A administração pública direta e indireta de qualquer dos Poderes da União, dos Estados, do Distrito Federal e dos Municípios obedecerá aos princípios de legalidade, impessoalidade, moralidade, publicidade e eficiência e, também, ao seguinte":
} 
blica não se furtou a essa transformação e os mecanismos de transparência foram ampliados pelos portais públicos. A Lei de Acesso à Informação trouxe o entendimento de transparência ativa e passiva ${ }^{5}$ como uma forma de diferenciar a disponibilização da informação pelo Estado.

A transparência ativa tem uma grande importância no acesso à informação, pois a disponibilização de dados em sites da internet, sem necessidade de provocação do cidadão, gera rapidez na consulta. Em geral, o que é disponibilizado nos portais decorre de obrigação legal, o que facilita a adoção de padrões na apresentação da informação ${ }^{6}$.

Por sua vez, a transparência passiva é entendida como a disponibilização da informação pública pelo órgão mediante provocação do cidadão, que solicita o documento, dado ou informação existente no Poder Público. A grande diferença entre essa solicitação com base na LAI e outros instrumentos utilizados para acesso a dados públicos (e.g. habeas data, mandado de segurança, pedido protocolado na repartição) é que não há necessidade de justificar o porquê da solicitação nem sua possível utilização posterior.

A transparência passiva ocasionou a grande alteração do paradigma do sigilo no Poder Público, pois somente se pode negar acesso a um documento produzido ou sob guarda da Administração Pública se estiver com restrição de acesso. E as possibilidades de restrição de acesso são residuais e estão previstas em lei. Logo, pressupõe-se que tudo é público até que o agente público apresente uma restrição de acesso legítima aos olhos da LAI.

Para que a transparência passiva pudesse ser instrumentalizada corretamente, foi previsto na LAI o Serviço de Informações ao Cidadão ${ }^{7}$ (SIC), no qual o interessado pode realizar seu pedido de acesso à informa-

$5 \quad$ Os termos transparência ativa e passiva não estão previstos na lei, mas são costumeiramente utilizados para explicar a diferença entre as informações publicadas nos portais de transparência e as solicitadas pelos serviços de informações ao cidadão.

$6 \quad$ No México, também é utilizado o recurso da previsão normativa de aumento de dados a serem disponibilizados (COSTA, 2017) e também é observada a dificuldade de tratar as diferenças regionais e de capacidade na publicação dessas informações. Entende-se que é mais fácil mudar as normas do que a realidade e o comportamento dos atores.

7 Este nome "Serviço de Informações ao Cidadão" não foi previsto como um nome próprio aos serviços de busca e fornecimentos de informações, definidos pela transparência passiva, mas é utilizado em nível federal e em grande parte dos entes subnacionais para identificar este canal. 
ção, diretamente e com base na LAI. O SIC é responsável por tramitar esse pedido e orientar a população sobre o direito de acesso à informação, além de possibilitar que uma resposta seja dada ao solicitante.

A LAI trouxe a previsão dos procedimentos, dos prazos e das instâncias recursais para o governo federal, mas os princípios de transparência e requisitos mínimos são de observância nacional. E, sendo essa uma lei nacional, ela deve ser regulamentada e implementada pelos demais Poderes e entes federativos, havendo previsão expressa, para tanto, no art. 45 da $\mathrm{LAI}^{8}$. A implementação nos entes subnacionais é apontada como um dos problemas para o sucesso da política pública nacional de acesso à informação (ANGELICO, 2012; ARRUDA, 2016; COSTA, 2017; MICHENER et al., 2018).

\subsection{TRANSPARÊNCIA PASSIVA E OS SICS}

O conceito de transparência passiva está intimamente relacionado aos serviços de informações ao cidadão, uma vez que são os responsáveis pelo recebimento, pelo processamento e pela resposta do pedido de informação recebido.

Os chamados Serviços de Informações ao Cidadão são os instrumentos para acesso do cidadão à informação, documentos e dados públicos por meio de pedidos ao Poder Público.

A LAI determina, no seu art. $9^{\circ}$, que tais serviços sejam criados em localização física, com condições apropriadas para atender e orientar presencialmente ao público, informar sobre a tramitação de documentos nas suas unidades e protocolizar documentos e requerimentos de acesso a informações. Além disso, há a necessidade de gerenciar o pedido de informação dentro da sua organização ou no ente federado.

Assim, o SIC não pode ser entendido apenas como um sistema eletrônico de recebimento e encaminhamento de pedidos, mas um amplo sis-

8 Art. 45. "Cabe aos Estados, ao Distrito Federal e aos Municípios, em legislação própria, obedecidas as normas gerais estabelecidas nesta Lei, definir regras específicas, especialmente quanto ao disposto no art. 9o e na Seção II do Capítulo III".

Rev. Controle, Fortaleza, v.19, n.2, p. 66-96, jul./dez. 2021. 
tema, com recursos humanos, organograma, fluxos e procedimentos definidos para o atendimento da lei. Como exemplo, temos o entendimento do estado de São Paulo, que, no exercício de sua competência regulamentar local, expediu um "Roteiro para a Instalação do Serviço de Informações ao Cidadão", utilizado no início da vigência da lei e que detalhava a estrutura física e os recursos necessários para a instalação do SIC nos órgãos da Administração Pública estadual, tais quais: i) designação do responsável SIC; ii) identificação do local onde o serviço será instalado; iii) recursos tecnológicos necessários, e iv) perfil esperado para o atendente SIC (que conheça a estrutura e o funcionamento do órgão, tenha bom relacionamento interpessoal para facilitar a busca pela informação e saiba utilizar os recursos tecnológicos mínimos). Porém, é comum se associar o SIC ao sistema eletrônico. Nas entrevistas realizadas para a pesquisa que originou este artigo, nos questionamentos aos responsáveis SIC, tinha de ser reiteradamente esclarecido que se questionava sobre a implantação do SIC em seu conceito amplo, não apenas a implantação do sistema eletrônico correlato.

Pelo fato de o SIC, previsto na LAI, ser um local para receber pedidos e protocolizar documentos, observou-se, na coleta dos dados, que houve uma associação prática com serviços de protocolo e de ouvidoria já estabelecidos nas organizações públicas.

Com relação à ouvidoria, a associação é frequente e observada em diversas capitais, inclusive sendo utilizados os mesmos sistemas eletrônicos para recebimentos de solicitação de informações previstas na LAI e demandas de ouvidoria. No governo federal, houve necessidade de integração entre o Sistema de Ouvidorias do Poder Executivo Federal (e-Ouv) e o Sistema Eletrônico do Serviço de Informações ao Cidadão (e-SIC), que gerou o chamado Fala.br para o direcionamento correto das informações recebidas por cada um dos canais.

Entretanto, as demandas de ouvidorias são diferentes dos pedidos

9 Disponível em: http://www.governoaberto.sp.gov.br/wp-content/uploads/2016/02/DGSAESP RoteiroSIC.pdf. Acesso em: 15 out. 2019. 
SIC. Os pedidos objetos do SIC são documentos e informações produzidos e acumulados pela Administração Pública. Já no Manual do SIC da $\mathrm{CGU}^{10}$ há clara diferenciação entre ambos, uma vez que as manifestações da ouvidoria seriam:

- Sugestão: proposição de ideia ou formulação de proposta de aprimoramento de políticas e serviços prestados pela Administração Pública federal.

- Elogio: demonstração ou reconhecimento, ou satisfação, sobre o serviço oferecido ou atendimento recebido.

- Solicitação: requerimento de adoção de providência por parte da Administração.

• Reclamação: demonstração de insatisfação relativa a serviço público.

- Denúncia: comunicação de prática de ato ilícito cuja solução dependa da atuação de órgão de controle interno ou externo.

Conforme diagnosticado no manual da $\mathrm{CGU}$ e no roteiro do estado de São Paulo, devido à escassez de recursos humanos e também à otimização dos recursos públicos é comum que SICs e ouvidorias ocupem o mesmo espaço e a mesma pessoa compartilhe ambas as atribuições ${ }^{11}$, devendo ser capaz de diferenciar o tratamento de demandas de naturezas diferentes.

Quanto aos sistemas informatizados, tais instrumentos são importantes para a facilidade na solicitação do cidadão e para o encaminhamento dentro da organização pública. A necessidade de sistema informatizado é apontada por Michener e outros (2018) como uma certeza para o sucesso na implementação dos SICs nos órgãos públicos ${ }^{12} \mathrm{e}$ um dos obstáculos para a implementação subnacional, por demandar recursos financeiros.

\footnotetext{
10 Disponível em: https://esic.cgu.gov.br/sistema/site/MANUAL\%20e-SIC\%20-\%20GUIA\%20DO\%20 SIC.pdf. Acesso em: 15 out. 2019.

11 Esta possibilidade é prevista tanto no Manual da CGU (2013) quanto no Manual do Estado de São Paulo (2012)

12 Mas não pode ser a única forma para solicitação de informações. No México, foi necessária a implementação de serviço telefônico para atendimento aos cidadãos que não tinham acesso à internet, anos após a regulamentação da lei de acesso do país.
} 


\section{FEDERAÇÃO E IMPLEMENTAÇÃO DA POLÍtiCA DE ACESSO À INFORMAÇÃO}

No Brasil, como um Estado federado, em que seus entes subnacionais têm autonomia executiva e legislativa, as leis emanadas do Congresso Nacional necessitam de complementação normativa e de criação de estruturas organizacionais locais. Dependem de um movimento subnacional de produção legislativa que vai desde leis orçamentárias para previsão de receitas, abertura de concurso público, alterações nos organogramas a eventuais produções normativas quando no exercício de competência concorrente e complementar, para que o comando normativo nacional tenha sua aplicação na esfera subnacional. Esse movimento se deu no caso da aplicação local da Lei n ${ }^{\circ} 12.527 / 2011$.

A Lei de Acesso à Informação prevê as diretrizes a serem seguidas pela União, estados, Distrito Federal e municípios, pelos Poderes Executivo, Legislativo e Judiciário, pelo Ministério Público e demais entidades que recebam recursos públicos, mas, em alguns artigos, prevê estruturas e procedimentos apenas para o Poder Executivo federal.

A própria LAI determina que estados, Distrito Federal e municípios a regulamentem, respeitando as normas gerais estabelecidas, em especial os serviços de informações ao cidadão, a divulgação da lei e os graus e procedimentos recursais ${ }^{13}$. Contudo, não apenas os entes subnacionais devem regulamentar, e não apenas esses pontos legais devem ser regulamentados pelos órgãos abrangidos pela LAI.

A norma local contribui para melhor definir as especificidades. Assim, não basta, no caso da transparência passiva da Lei de Acesso à Informação, disponibilizar um canal para recebimento das demandas; é necessário definir prazos, fluxos, responsáveis e graus recursais. Também não basta definir todos os pontos e regulamentar a lei sem que haja um 13 Lei n ${ }^{\circ} 12.527 / 2011$ - “Art. 45. Cabe aos Estados, ao Distrito Federal e aos Municípios, em legislação própria, obedecidas as normas gerais estabelecidas nesta Lei, definir regras específicas, especialmente quanto ao disposto nos art. $9^{\circ}$ e na Seção II do Capítulo III". 
esforço da Administração Pública para que o serviço funcione e alcance os seus propósitos.

Em Estados federados, quando há necessidade de regulamentação normativa pelos entes subnacionais, podem ser observadas repetições de textos normativos e de estruturas entre estados, municípios e o Distrito Federal. Inclusive, observou-se, na coleta de dados, que houve uma espera, por parte dos entes subnacionais, por orientações federais para a regulamentação e a implementação da política local de acesso à informação. Esse fenômeno de espera de regulamentação federal pôde ser observado em 17 capitais, objeto desta pesquisa, que iniciaram o processo de regulamentação local da LAI a partir de 2013, ou seja, um ano após a entrada em vigor da lei e um ano após a regulamentação federal.

A LAI, diferentemente da Lei Complementar $n^{\circ} 131 / 2009$, que alterou a Lei Complementar $n^{\circ} 101 / 2000$, não tem previsão de sanção expressa caso os entes subnacionais não a regulamentem ou implementem no seu âmbito de atuação, tampouco estabeleceu prazo para essa regulamentação. Na Lei Complementar n ${ }^{0}$ 131/2009, há a previsão de impedimento de transferências voluntárias, caso não houvesse transparência, quer dizer, divulgação ampla de informações sobre receitas e despesas por prazos determinados pela própria Lei Complementar $n^{0} 131 / 2009^{14}$.

\footnotetext{
14 LC n ${ }^{\circ} 101 / 2000$ alterada pela $\mathrm{LC} \mathrm{n}^{\circ}$ 131/2009: “Art. 23. [...] § 3o Não alcançada a redução no prazo estabelecido, e enquanto perdurar o excesso, o ente não poderá:

I - receber transferências voluntárias;

$[\ldots]$

Art. 48. São instrumentos de transparência da gestão fiscal, aos quais será dada ampla divulgação, inclusive em meios eletrônicos de acesso público: os planos, orçamentos e leis de diretrizes orçamentárias; as prestações de contas e o respectivo parecer prévio; o Relatório Resumido da Execução Orçamentária e o Relatório de Gestão Fiscal; e as versões simplificadas desses documentos.

Parágrafo único. A transparência será assegurada também mediante:

I - incentivo à participação popular e realização de audiências públicas, durante os processos de elaboração e discussão dos planos, lei de diretrizes orçamentárias e orçamentos;

II - liberação ao pleno conhecimento e acompanhamento da sociedade, em tempo real, de informações pormenorizadas sobre a execução orçamentária e financeira, em meios eletrônicos de acesso público;

III - adoção de sistema integrado de administração financeira e controle, que atenda a padrão mínimo de qualidade estabelecido pelo Poder Executivo da União e ao disposto no art. 48-A.

Art. 48-A. Para os fins a que se refere o inciso II do parágrafo único do art. 48, os entes da Federação disponibilizarão a qualquer pessoa física ou jurídica o acesso a informações referentes a:

I - quanto à despesa: todos os atos praticados pelas unidades gestoras no decorrer da execução da despesa, no momento de sua realização, com a disponibilização mínima dos dados referentes ao número do correspondente processo, ao bem fornecido ou ao serviço prestado, à pessoa física ou jurídica beneficiária do pagamento e, quando for o caso, ao procedimento licitatório realizado;
} 
A LAI não tem essa previsão nem garantia de repasse financeiro para colaborar na implementação da política de acesso à informação. Não há um modelo ideal definido em lei, além de um rol mínimo de transparência ativa exigida dos entes federativos. Esses pontos tornaram a implantação da política pública de acesso à informação uma tarefa de complexa execução para atender aos requisitos internacionais. Na ausência de um comando legal, as boas práticas de transparência e acesso à informação se tornaram essenciais para guiar os agentes públicos na implantação da LAI localmente. Como observado na coleta de dados, a replicação dessas boas práticas ocorreu em muitas capitais de estados, induzindo a uma homogeneização de estruturas e fluxos de trabalho nas cidades pesquisadas.

Pela teoria das instituições, é possível explicar os fenômenos políticos e suas alterações. Alterações de comportamentos organizacionais podem ser analisados de diversas formas e, neste trabalho, a teoria institucional apresenta uma relevância na análise das estruturas existentes e necessárias para a implementação da LAI e dos SICs (HALL; TAYLOR, 2003).

As instituições fornecem modelos morais e cognitivos que envolvem o indivíduo e afetam a sua identidade, imagem e preferências em realizar suas ações. E elas resistem ao serem radicalmente confrontadas, pois, a partir das suas mudanças e decisões, o indivíduo pode adotar eventual reforma afetando as estruturas das instituições (HALL; TAYLOR, 2003).

O ambiente institucional ampliou sua definição com uma nova con-

II - quanto à receita: o lançamento e o recebimento de toda a receita das unidades gestoras, inclusive referente a recursos extraordinários.

$[\ldots]$

Art. 73-B. Ficam estabelecidos os seguintes prazos para o cumprimento das determinações dispostas nos incisos II e III do parágrafo único do art. 48 e do art. 48-A:

I - 1 (um) ano para a União, os Estados, o Distrito Federal e os Municípios com mais de 100.000 (cem mil) habitantes;

II - 2 (dois) anos para os Municípios que tenham entre 50.000 (cinquenta mil) e 100.000 (cem mil) habitantes;

III - 4 (quatro) anos para os Municípios que tenham até 50.000 (cinquenta mil) habitantes.

Parágrafo único. Os prazos estabelecidos neste artigo serão contados a partir da data de publicação da lei complementar que introduziu os dispositivos referidos no caput deste artigo.

Art. 73-C. O não atendimento, até o encerramento dos prazos previstos no art. 73-B, das determinações contidas nos incisos II e III do parágrafo único do art. 48 e no art. 48-A sujeita o ente à sanção prevista no inciso I do $\S 30$ do art. 23." 
ceituação do campo organizacional. DiMaggio e Powell (RIBEIRO et al., 2016) definem campo organizacional como um conjunto de organizações que integram uma área institucional. E os processos de institucionalização e isomorfismo têm dependência de condição com essa evolução social e histórica (RIBEIRO et al., 2016).

O isomorfismo, no caso da LAI, pôde ser observado na modalidade isomorfismo competitivo, decorrente das avaliações e das classificações sobre a LAI, realizadas por organização pública (CGU) e privada (FGV). Também foi observado o isomorfismo coercitivo pelo fato de normas gerais e requisitos mínimos estarem previstos na lei nacional. A pressão internacional para a abertura de dados e a utilização pela mídia dos dados disponibilizados com base na LAI são outras formas de observar o isomorfismo coercitivo.

O isomorfismo mimético pôde ser observado entre os entes públicos pela quebra de paradigma: do sigilo à transparência. O sigilo passa a ser exceção, e a publicidade, a regra, além da previsão da possibilidade de o cidadão solicitar qualquer informação de forma mais prática, sem justificar e com prazo preestabelecido a ser cumprido pela Administração Pública. Tal alteração de paradigma, em um cenário de incerteza, contribuiu para que os modelos adotados fossem semelhantes aos que estavam mais adiantados em outras capitais, utilizando-se de práticas de serviços existentes, como protocolos, ouvidorias e canais de recebimento de serviços.

As estruturas utilizadas e os profissionais envolvidos podem ser fontes de isomorfismo normativo. Observou-se, na coleta dos dados, que o fato de, em nível federal, um órgão de controle interno (CGU) ter fundamental papel na implementação da LAI gerou replicação de modelo nos entes subnacionais. Com algumas exceções, os órgãos que capitanearam a implementação e o monitoramento da LAI, nas capitais brasileiras, foram os de controle interno. Os dados obtidos nas entrevistas apontam para a conclusão de que o advento da LAI colaborou para a reestruturação dos entes públicos e dos próprios órgãos de controle interno. Assim, características de isomorfismo 
foram observadas nas capitais dos estados brasileiros. Todavia, a replicação de modelos não pode ser dada como garantia de eficiência no processo de implantação da política pública (DIMAGGIO; POWELL, 2005).

\section{ANÁLISE NORMATIVA DAS 26 CAPITAIS}

A importância da regulamentação normativa local da Lei de Acesso à Informação foi destacada neste trabalho. A análise dessas regulamentações buscou explicar como funciona, nas 26 capitais brasileiras, excluído o Distrito Federal, o Serviço de Informações ao Cidadão, qual a sua estrutura organizacional e o fluxo interno na instituição para o atendimento da demanda.

Durante esta análise, foram realizadas as classificações por categoria.

Categoria normativa adotada para a regulamentação da LAI:

- 3 por lei

- 18 por decreto

- 5 por lei e decreto

Não há uma imposição legal sobre a regulamentação da LAI, por lei ou por decreto. Cada gestor analisou a melhor configuração normativa local para o ente e verificou os atores envolvidos nesse processo. Ambos os tipos normativos têm vantagens e desvantagens, sendo possível a escolha pela Administração Pública de qual o modelo a ser adotado.

A seguir, há um quadro elaborado pela CGU publicado no seu Guia técnico de regulamentação da Lei de Acesso à Informação em Municípios e checklist sobre as diferenças entre lei e decreto no que tange à LAI: 
Tabela 1 - Diferenças entre lei e decreto na regulamentação subnacional da LAI

\begin{tabular}{|c|c|c|c|}
\hline Norma & Rito de Aprovação & Força Normativa & Abrangência \\
\hline Lei & $\begin{array}{l}\text { - Submete-se ao } \\
\text { processo legislativo } \\
\text { municipal; } \\
\text { - Via de regra, a } \\
\text { Câmara Municipal } \\
\text { discute e aprova e o } \\
\text { Prefeito sanciona. }\end{array}$ & $\begin{array}{l}\text { - A Lei é um ato normativo } \\
\text { primário, ou seja, pode inovar } \\
\text { a ordem jurídica, e tem maior } \\
\text { força normativa e figura no topo } \\
\text { da hierarquia das normas locais; } \\
\text { - A Lei pode inovar na esfera } \\
\text { jurídica, instituindo novos } \\
\text { elementos para a lei de acesso. }\end{array}$ & $\begin{array}{l}\text { - Pode vincular toda a } \\
\text { Administração Pública } \\
\text { Municipal, abrangendo } \\
\text { os Poderes Executivo e } \\
\text { Legislativo. }\end{array}$ \\
\hline Decreto & $\begin{array}{c}\text { - Não se submete ao } \\
\text { processo legislativo; } \\
\text { - Processo mais } \\
\text { célebre; } \\
\text { - É elaborada e } \\
\text { assinada pelo Prefeito. }\end{array}$ & $\begin{array}{l}\text { - Trata-se de ato administrativo; } \\
\text { - Apresenta detalhamentos e } \\
\text { procedimentos, sem inovação } \\
\text { jurídica; } \\
\text { - Em geral, por se tratar de ato } \\
\text { normativo secundário, apenas } \\
\text { regulamenta a lei, especificando } \\
\text { seus mandamentos gerais da Lei. }\end{array}$ & $\begin{array}{c}\text { - Restrita apenas } \\
\text { à Administração } \\
\text { Pública Direta ou } \\
\text { Indireta Autárquica e } \\
\text { Fundacional do Poder } \\
\text { Executivo Municipal. }\end{array}$ \\
\hline
\end{tabular}

Fonte: Adaptada da CGU (2013).

Das capitais que optaram pela publicação exclusiva de lei (Goiânia, João Pessoa e Macapá) ou pela publicação conjunta de lei e decreto (Cuiabá, Recife, Rio Branco, Salvador e Vitória), todas inovaram na esfera jurídica, prevendo um, dois ou quatro graus recursais para o pedido de acesso à informação. É certo que a Lei $n^{\circ} 12.527 / 2011$, neste ponto de recursos, tem aplicabilidade federal, devendo cada ente federativo adequá-la à sua realidade, produzindo as normas locais.

Cuiabá também regulamentou por lei, mas previu três graus recursais; no entanto, não seguiu exatamente o previsto na lei federal, sendo uma regulamentação confusa, em que há previsão do primeiro recurso para o órgão de controle interno, mas com apreciação preliminar da autoridade hierarquicamente superior, sem previsão clara de prazos e procedimentos. Cuiabá também inovou quanto ao prazo para entrega inicial da informação, reduzindo-o para 15 dias.

Os prazos também são as maiores alterações observadas nas re- 
gulamentações das capitais, em relação aos estabelecidos pela LAI, em especial para a apreciação recursal. O prazo para atendimento inicial do pedido com base na LAI segue, em sua maioria, os 20 dias prorrogáveis por mais dez dias, exceto Cuiabá e Palmas, que preveem um prazo de 15 dias, prorrogáveis por mais dez dias, sendo mais benéfico para o cidadão e impondo uma pressão maior sobre a Administração Pública.

Nos prazos para apreciação recursal, há uma variação maior entre as capitais, em especial quando a estrutura prevista é muito distinta da previsão federal. No entanto, no geral, os prazos para apreciação por parte dos órgãos recursais são de dez dias, diferentemente do previsto na LAI para a apreciação da autoridade, e da CGU, que é de cinco dias. Uma hipótese possível para justificar isso seria que tal alteração, embora seja prejudicial ao cidadão, trata-se de uma adequação estrutural para melhor atender ao propósito da lei de acesso.

O Programa de Transparência Pública da FGV, na sua pesquisa sobre transparência local (MICHENER, 2016), não avaliou especificamente os prazos recursais, mas o funcionamento da instância recursal para conseguir a informação. O resultado da avaliação não foi positivo.

Categoria sobre graus recursais:

- 2 com quatro (4) graus

- 9 com três (3) graus

- 10 com dois (2) graus

- 5 com um (1) grau

Dessa classificação, foi observada a repetição da estrutura federal em entes subnacionais, neste caso, em 9 capitais (Belém, Belo Horizonte, Boa Vista, Cuiabá, Fortaleza, Manaus, Porto Velho, São Luís, São Paulo) que, além de prever a mesma quantidade de graus recursais, preveem órgãos de mesma atribuição ou semelhantes, seguindo o modelo da CGU: 


\section{Federal - Lei}

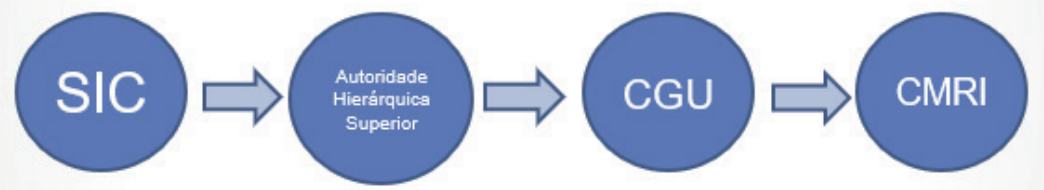

Fonte: Elaborada pelas autoras com base na Lei n ${ }^{\circ} 12.527 / 2011$.

Figura 2 - Graus recursais em nove capitais

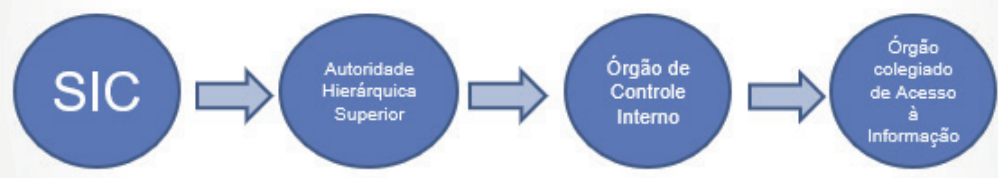

Fonte: Elaborada pelas autoras com base nas normativas das capitais, elencadas na Tabela Anexo.

Da análise das normativas, não se pôde afirmar que, mesmo prevendo uma estrutura recursal semelhante à da CGU, houve uma repetição das normativas federais. A Lei $n^{\circ} 12.527 / 2011$ é uma lei nacional e necessitou de regulamentação do próprio Poder Executivo federal, realizada por meio do Decreto $n^{\circ} 7.724 / 2012$. No Decreto federal, foi previsto que, caso não fosse cumprida a determinação de entrega da informação, poderia o solicitante realizar uma reclamação à autoridade de monitoramento. 


\section{Federal - Lei e Decreto}
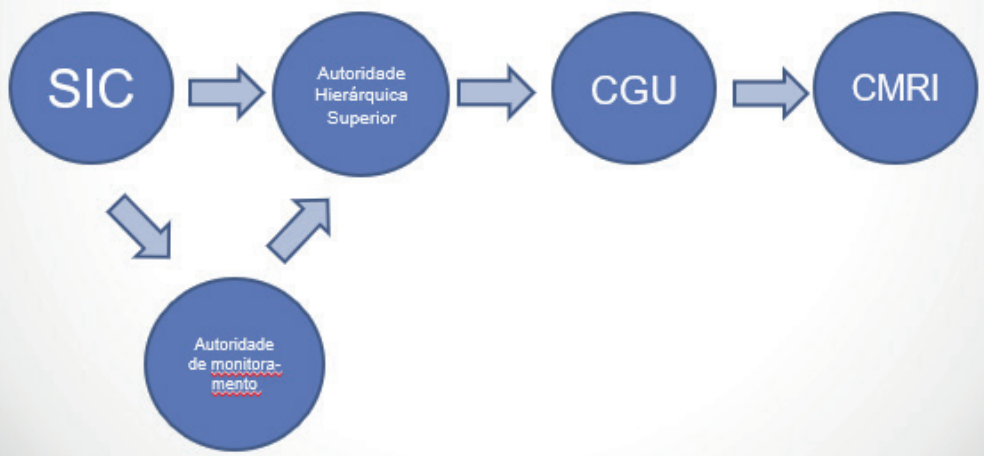

Fonte: Elaborada pelas autoras com base na Lei n ${ }^{\circ} 12.527 / 2011$ e no Decreto n ${ }^{\circ} 7.724 / 2012$.

A previsão da autoridade de monitoramento, como instância para reclamação, está prevista nas estruturas normativas de Fortaleza, João Pessoa, Palmas, Porto Velho, Salvador e Vitória. No caso de Salvador e Vitória, há diferenciação de modelo, uma vez que não há previsão de encaminhamento de novo recurso para um órgão de controle interno. As cidades de João Pessoa e de Palmas também se diferenciam pela quantidade de graus recursais, que são quatro.

Os dados coletados apontam que não houve uma repetição integral entre o previsto nas normas federais e das capitais estudadas, destacadamente no que concerne à estipulação de prazos para apreciação recursal pela autoridade hierarquicamente superior. Das nove capitais com estrutura recursal semelhante à prevista no nível federal, somente Boa Vista, Fortaleza, Manaus, Porto Velho e São Paulo, ou seja, um pouco mais da metade, têm a previsão de prazo para a apreciação de recurso igual ao federal, que é de cinco dias. 
Assim, regulamentação igual ao previsto para o Poder Executivo federal, com três graus recursais, reclamação para autoridade de monitoramento e prazo de apreciação de cinco dias para a autoridade hierarquicamente superior, somente foi encontrada em Fortaleza e em Porto Velho.

Com as análises normativas, também foi observado que houve um esforço em adaptar as estruturas e os procedimentos da LAI à realidade local. Nove capitais publicaram as regulamentações da LAI em 2012, ano da entrada em vigor da lei, sendo que seis publicaram em maio de 2012, mês da entrada em vigor. Assim, oficialmente, não se sabia como seria a regulamentação federal por decreto, pois se tinha como base apenas a LAI. Após a expedição do decreto federal, dessas nove capitais três revogaram suas normativas e publicaram novas normas, e outras três alteraram seus dispositivos.

Das três que mantiveram suas normativas sem alterações - Curitiba, Florianópolis e Vitória -, as estruturas e os fluxos previstos não são semelhantes aos previstos nas normas federais. É importante observar que Curitiba é a única, entre as capitais, que previu a gestão documental na sua regulamentação, sendo o Arquivo Público Municipal o responsável pela gestão transparente dos documentos. Também cabe observar que, entre as capitais, apenas Florianópolis não obteve notas elevadas nas avaliações da FGV e CGU - essas avaliações fazem parte dos documentos analisados para este artigo.

A regulamentação de Cuiabá não é clara quanto aos prazos recursais e às suas autoridades. Depreende-se, da lei, que o cidadão tem dez dias para entrar com recurso na Controladoria Geral do Município (CGM), porém, antes, deve haver uma apreciação da autoridade recursal, não tendo sido definindo prazo para isso.

Em João Pessoa, há a previsão normativa de quatro graus recursais e que, após dez pedidos sobre o mesmo assunto, este deve ser convertido em informação a ser fornecida pela transparência ativa, isto é, deve ser 
publicado no Portal da Transparência. Em Macapá, há previsão de recurso de ofício para o órgão colegiado. E, em Florianópolis, o recurso de ofício é para o ouvidor-geral do município. Rio Branco também tem recurso de ofício para o prefeito, como última instância recursal. Em Natal, a autoridade que analisa o primeiro recurso é a mesma que exarou a primeira resposta.

Segundo as normativas analisadas, em Recife são utilizadas a sigla PAI - Pedido de Acesso à Informação e SAI - Serviço de Acesso à Informação, em substituição ao SIC. E, em Manaus, o decreto revogado utilizava SAI. Já em Salvador, há a previsão de abuso do direito de pedir, por parte do cidadão.

Em 12 capitais (Aracaju, Belém, Belo Horizonte, Cuiabá, Fortaleza, Macapá, Manaus, Palmas, Rio de Janeiro, Salvador, Teresina, São Paulo), a ouvidoria faz parte da estrutura de acesso à informação prevista nas regulamentações de forma explícita. Das 26 capitais que tiveram suas regulamentações analisadas, apenas Curitiba não tem a participação de algum órgão de controle interno ${ }^{15}$ na estrutura de funcionamento da LAI. Em alguns casos, o pedido inicial é recebido por setores alheios a qualquer órgão de controle interno, mas há a participação de algum órgão de controle interno como uma das autoridades recursais, conforme previsto em Porto Velho.

\subsection{OUVIDORIA $\times$ SIC}

As ouvidorias públicas no Brasil começaram a ser instituídas com a redemocratização nos anos de 1980, com a ideia da instituição sueca do ombudsman como um órgão público responsável por acolher as expectativas sociais e a introduzi-las no Estado ${ }^{16}$.

15 Segundo o modelo da CGU e a PEC n ${ }^{\circ} 45 / 2009$, o controle interno é constituído de quatro macrofunções: auditoria governamental, controladoria, correição e ouvidoria. Não são todos os órgãos centrais de controle interno (controladorias gerais ou secretarias) que têm essas quatro macrofunções.

16 CGU. História das ouvidorias. Disponível em: https://www.gov.br/ouvidorias/pt-br/cidadao/conheca-a-ouvidoria/historia-das-ouvidorias\#: :text=A\%20primeira $\% 20$ ouvidoria $\% 20 \mathrm{p} \% \mathrm{C3} \% \mathrm{BAblica} \% 20 \mathrm{brasileira}$,participa $\%$ C3\%A7\%C3\%A30\%20nas\%20delibera \%C3\%A7\%C3\%B5es\%20do\%20Estado. Acesso em: 1 out. 2020. 
Os Poderes e entes federados instituíram suas ouvidorias, tendo a necessidade de estruturá-las para o recebimento das demandas dos cidadãos, em especial a respeito dos serviços prestados pelo Estado.

Quando houve a publicação da Lei de Acesso à Informação, observou-se alguma similaridade com o serviço de ouvidoria. Porém, como já apresentado, o objeto da LAI é diferente das demandas destinadas à ouvidoria, bem como se afasta de suas competências institucionais previstas na Lei $n^{\circ}$ 13.460/2017. No entanto, a integração entre ouvidorias e SICs foi realidade em muitos entes federados, seja com o ouvidor como responsável pelo atendimento do SIC, seja com a ouvidoria como órgão recursal no fluxo da demanda da LAI.

Há, explicitamente, nas normativas de regulamentação das 12 capitais a previsão de que a ouvidoria faz parte da estrutura do atendimento ao acesso à informação, sendo que em nove capitais são a porta de entrada dessas demandas.

Aracaju, Belém, Belo Horizonte, Florianópolis, Salvador e Rio de Janeiro recebem as demandas pelo mesmo sistema das demandas de ouvidorias. Em especial, Salvador e Rio de Janeiro recebem as demandas pelo mesmo canal de todos os serviços do município (Fala Salvador e Sistema 1746, respectivamente). O fato de receberem demandas diversas pelo mesmo canal pode alterar o tratamento que deve ser dado aos pedidos SIC e o cumprimento de prazos e recursos, além de interferir nos dados estatísticos sobre a quantidade de demanda recebida pelos órgãos.

Analisando os relatórios estatísticos dos SICs de Belo Horizonte e de Salvador, foi verificado que há uma subjetividade no encaminhamento das demandas para tratamento nas ouvidorias e nos SICs. Essas duas capitais recebem as demandas de LAI e de ouvidoria pelo mesmo canal. Pelas informações do censo do IBGE de 2010, o número de habitantes de ambas é bem semelhante, sendo Salvador mais populosa. No entanto, pelos relatórios no ano de 2018 Salvador recebeu 181 pedidos com base na LAI, e Belo Horizonte, 1157. 
Tais números tão discrepantes em capitais com a quantidade de habitantes equivalentes podem levar ao questionamento sobre o impacto da subjetividade nos atos de classificar e de encaminhar as demandas de ouvidoria e de LAI, o que poderia ser objeto de uma pesquisa específica. A importância do encaminhamento correto do que seja uma demanda de SIC e uma demanda de ouvidoria, além de gerar um bom fluxo da informação na estrutura da Administração Pública municipal, abre a possibilidade de o usuário solicitar a revisão (recurso) em caso de negativa de acesso à informação.

Outro ponto observado é que a profusão de canais de recebimento de demandas do cidadão, além de inflar os números nos relatórios estatísticos, pode gerar tratamentos díspares, fornecendo respostas diversas, para o mesmo fato, ao cidadão demandante. Quando o ouvidor é o responsável pelos dois canais, essa possibilidade diminui. Entretanto, em municípios maiores, como é o caso das capitais, dificilmente é o ouvidor o responsável exclusivo por essas demandas, conforme observado nas entrevistas realizadas, mas sim a equipe da ouvidoria, sendo um grupo de servidores que recebem essas duas demandas e devem tratá-las de forma correta.

Como já referido, em nível federal, houve uma alteração e a Controladoria Geral da União unificou os dois canais de recebimento de demandas de ouvidoria e da LAI, tendo sido disponibilizado, em agosto de 2019, o módulo de acesso à informação do Fala.Br. Esse sistema tem um módulo próprio que também pode ser utilizado pelos entes subnacionais e poderia facilitar a unificação dos canais de ouvidoria e de acesso à informação nos municípios.

\section{CONSIDERAÇÕES FINAIS}

A Lei de Acesso à Informação - Lei no 12.527/2011 busca quebrar o paradigma do sigilo na Administração Pública prevendo que a transparência é a regra, e a exceção é a restrição de acesso à informação. A sua 
importância para a abertura de dados e o controle social é enorme, mas, para que se efetive essa mudança, são necessárias alterações nos fluxos e nos processos da gestão pública nos entes federativos subnacionais, bem como a construção de um suporte normativo complementar local.

Como essa lei altera procedimentos e determina a criação de serviço de informação ao cidadão em todos os Poderes e entes federados, a sua regulamentação e a sua implementação não são automáticas. O fato de o Brasil ser uma federação contribuiu para a dificuldade na sua regulamentação nos entes subnacionais, diante da grande pulverização de entes federados, com autonomia constitucional garantida. No entanto, a CGU se propôs a coordenar essa mudança em nível nacional e ofereceu subsídios técnicos, normativos e institucionais para que a LAI fosse implementada em âmbito nacional.

Ao estudar os SICs nas capitais brasileiras, sob a óptica das teorias institucional e do isomorfismo, observou-se que as capitais seguiram a tendência de similaridade, buscando legitimarem-se, e utilizaram os modelos já existentes, em nível federal, como base para implementar localmente a política pública de acesso à informação.

O isomorfismo, como hipótese inicial da pesquisa, foi confirmado pela análise qualitativa realizada, tanto nas estruturas quanto nos procedimentos adotados pelas capitais brasileiras, no âmbito da implantação do SIC.

Ao longo da pesquisa, com as leituras dos documentos e com a coleta dos dados, observou-se que a competição entre as capitais, para figurar bem nas avaliações que foram realizadas pela FGV e pela CGU, reforçou a busca por replicação de estruturas e de procedimentos que tenham sido bem pontuados nessas avaliações como uma forma de emulação de melhores práticas.

No que concerne à modelagem dos graus recursais aplicáveis à LAI, observou-se que houve uma maior variação e liberdade de adoção de modelos entre as capitais, com maior flexibilidade de acordo com a 
realidade institucional local.

As estruturas organizacionais das capitais foram mapeadas e relacionadas. Observou-se a utilização de estruturas organizacionais já existentes, como as das ouvidorias. Da mesma forma, verificou-se a importância dos órgãos de controle interno para a implementação e para a fiscalização da aplicação da LAI e dos SICs nas capitais.

Observou-se, igualmente, o isomorfismo nas regulamentações locais, quando comparado com o marco normativo federal, com grande influência da CGU. Seja pelo Programa Brasil Transparente, seja pela avaliação do Escala Brasil Transparente, o suporte da CGU foi visto como essencial para a implementação dos SICs nas capitais. Esse espelhamento também foi verificado pelo fato de a implementação da LAI, localmente, ter a participação dos órgãos de controle interno (ouvidorias), o que pode ter colaborado para as reestruturações das controladorias e das ouvidorias nas capitais.

A repetição de modelos entre as capitais também foi observada na utilização de sistema informatizado, como canal principal para recebimento de demandas da LAI, ou no fato de, em alguns casos entrevistados, o canal de recebimento ser único para SIC e ouvidoria, havendo uma colaboração entre os serviços.

A pesquisa alcançou o objetivo de realizar um diagnóstico preliminar sobre as estruturas utilizadas nos SICs, de 2012 a janeiro de 2020, e a sua relação com o modelo federal e com modelos de outras capitais para sua implantação nas 26 capitais brasileiras. Novas análises seriam interessantes, por exemplo, pesquisas sobre a eficiência dos recursos administrativos para o acesso à informação, ou avaliações sobre se a utilização de sistemas únicos informatizados colabora para a qualidade das respostas, ou, ainda, sobre o fortalecimento ou não dos órgãos de controle interno, com a publicação de leis como a LAI. 


\section{REFERÊNCIAS}

ABRUCIO, F. Descentralização e coordenação federativa no Brasil: lições dos Anos FHC. In: O Estado numa Era das Reformas: os anos FHC. Brasília: MP, Seges, 2002. v. II.

ANGÉLICO, F. Lei de acesso à informação pública e seus possíveis desdobramentos para a accountability democrática no Brasil. 2012. 133 f. Dissertação (Mestrado em Administração Pública e Governo) Fundação Getúlio Vargas, São Paulo, 2012.

ARQUIVO PÚBLICO DO ESTADO. Roteiro para a instalação do Serviço de Informações ao Cidadão: ação estratégica para a implementação do Decreto no 58.052/2012. São Paulo, 2012. Disponível em: http://www.governoaberto.sp.gov.br/wp-content/uploads/2016/02/ DGSAESP_RoteiroSIC.pdf. Acesso em: 15 out. 2019.

ARRETCHE, M. Políticas sociais no Brasil: descentralização em um Estado federativo. RBCS, [s. l.], v. 14, n. 40, p. 111-141, 1999.

ARRUDA, C. E. G. Transparência subnacional: um estudo das variáveis determinantes para o atendimento da Lei de Acesso à Informação nos municípios brasileiros. 2016. 115 f. Dissertação (Mestrado em Administração Pública e Governo) - Fundação Getúlio Vargas, São Paulo, 2016.

BRASIL. [Constituição (1988)]. Constituição da República Federativa do Brasil. Brasília, DF: Presidência da República, 1988. Disponível em: http://www.planalto.gov.br/ccivil_03/constituicao/constituicao.htm. Acesso em: 6 jul. 2018. 
BRASIL. Decreto $\mathbf{n}^{\mathbf{0}} \mathbf{7 . 7 2 4 / 2 0 1 2}$, de 16 de maio de 2012. Regulamenta a Lei ${ }^{\circ} 12.527$, de 18 de novembro de 2011, que dispõe sobre o acesso a informações previsto no inciso XXXIII do caput do art. $5^{\circ}$, no inciso II do $\S 3^{\circ}$ do art. 37 e no $\S 2^{\circ}$ do art. 216 da Constituição. Disponível em: http:// www.planalto.gov.br/ccivil_03/_ato2011-2014/2012/decreto/d7724.htm. Acesso em: 6 jul. 2018.

BRASIL. Lei no 13.460, de 26 de junho de 2017. Dispõe sobre participação, proteção e defesa dos direitos do usuário dos serviços públicos da administração pública. Disponível em: http://www.planalto. gov.br/ccivil_03/_ato2015-2018/2017/lei/113460.htm. Acesso em: 22 mar. 2021.

BRASIL. Lei $\mathbf{n}^{\mathbf{0}} \mathbf{1 2 . 5 2 7}$, de 18 de novembro de 2011. Regula o acesso a informações previsto no inciso XXXIII do art. $5^{\circ}$, no inciso II do $\S 3^{\circ}$ do art. 37 e no $\S 2^{\circ}$ do art. 216 da Constituição Federal; altera a Lei $n^{\circ}$ 8.112, de 11 de dezembro de 1990; revoga a Lei n ${ }^{\circ} 11.111$, de 5 de maio de 2005, e dispositivos da Lei ${ }^{\circ}$ 8.159, de 8 de janeiro de 1991; e dá outras providências. Disponível em: http://www.planalto.gov.br/ccivil_03/_ ato2011-2014/2011/lei/112527.htm. Acesso em: 6 jul. 2018.

BRASIL. Lei Complementar $\mathbf{n}^{\mathbf{0}}$ 101, de 04 de maio de 2000. Estabelece normas de finanças públicas voltadas para a responsabilidade na gestão fiscal e dá outras providências.

Disponível em: http://www.planalto.gov.br/ccivil_03/leis/lcp/lcp101.htm. Acesso em: 6 set. 2019.

BRASIL. Lei Complementar $\mathbf{n}^{\mathbf{0}}$ 131, de 27 de maio de 2009. Acrescenta dispositivos à Lei Complementar $n^{\circ} 101$, de 4 de maio de 2000, que estabelece normas de finanças públicas voltadas para a responsabilidade na gestão fiscal e dá outras providências, a fim de determinar a 
disponibilização, em tempo real, de informações pormenorizadas sobre a execução orçamentária e financeira da União, dos Estados, do Distrito Federal e dos Municípios. Disponível em: http://www.planalto.gov.br/ ccivil_03/leis/lcp/lcp131.htm. Acesso em: 6 set. 2019.

CGU. Manual da Lei de Acesso à Informação para estados e municípios. Brasil Transparente. Brasília, 2013. Disponível em: https:// www.gov.br/cgu/pt-br/centrais-de-conteudo/publicacoes/transparenciapublica/brasil-transparente/arquivos/manual_lai_estadosmunicipios.pdf. Acesso em: 19 dez. 2018.

\section{CGU. Guia técnico de regulamentação da Lei de Acesso à Informação} em municípios e checklist. Brasil Transparente. Brasília, 2013. Disponível em: https://www.gov.br/cgu/pt-br/centrais-de-conteudo/publicacoes/ transparencia-publica/brasil-transparente/arquivos/guia_checklist.pdf. Acesso em: 19 dez. 2018.

\section{CGU. Relatório sobre a implementação da Lei de Acesso à Informação.} Brasília, 2017. Disponível em: http:/www.acessoainformacao.gov.br/ central-de-conteudo/publicacoes/relatorio-2017-web.pdf. Acesso em: 14 dez. 2019.

CGU. Manual do Fala.br: Módulo Acesso à Informação - Guia para SICs. STPC: Brasília, 2020. Disponível em: https://repositorio.cgu.gov. br/bitstream/1/46648/1/Manual_FalaBr_SIC_versao2.pdf. Acesso em: 1 out. 2020.

COSTA, A. B. L. da. Transparência e seus avessos: direito de acesso à informação no México. 2017. 232 f. Dissertação (Mestrado) - Faculdade de Comunicação, Universidade de Brasília. 2017. Disponível em: https:// repositorio.unb.br/handle/10482/24232. Acesso em: 7 abr. 2021. 
DIMAGGIO, P. J.; POWELLW.W.Agaiola de ferro revisitada: isomorfismo institucional e racionalidade coletiva nos campos organizacionais. RAE: Revista de Administração de Empresas, v. 45, n. 2, p.74-89, abr./jun. 2005.

MICHENER, G. (org.). Transparência local no Brasil: avaliando a aplicação da Lei de Acesso nos estados e nas grandes cidades. Rio de Janeiro: Fundação Getúlio Vargas: Open Society Foundations, 2016.

MICHENER, G.; CONTRERAS, E.; NISKIER, I. Da opacidade à transparência? Avaliando o acesso à informação no Brasil cinco anos depois. Rev. Adm. Pública, Rio de Janeiro, v. 52, n. 4, p. 610-629, jul./ ago. 2018. Disponível em: https://www.scielo.br/scielo.php?script=sci arttext\&pid=S0034-76122018000400610\&lng=en\&tlng=en. Acesso em: 16 jan. 2019. http://dx.doi.org/10.1590/0034-761220170289.

RIBEIRO, R. J. B.; BLIACHERIENE, A. C.; SANTANA, J. L. Considerações sobre formas, processos e isomorfismo nas estruturas de controle interno da federação brasileira. In: BLIACHERIENE, A. C.; BRAGA, M. V. A.; RIBEIRO, R. J. B. (coord.). Controladoria no setor público. Belo Horizonte: Fórum, 2016. p. 25-36.

\section{SITES}

CGU: https://www.gov.br/cgu/pt-br/assuntos/transparencia-publica/brasil-transparente

ESCALA BRASIL TRANSPARENTE:https://www.gov.br/cgu/pt-br/assuntos/transparencia-publica/escala-brasil-transparente

FALA.BR: https://sistema.ouvidorias.gov.br/publico/Manifestacao/SelecionarTipoManifestacao.aspx?ReturnUrl=\%2f 
IBGE: https://cidades.ibge.gov.br/

MPF: http://www.rankingdatransparencia.mpf.mp.br/

OGU: http://www.ouvidorias.gov.br

\section{ANEXO - REGULAMENTAÇ̃̃O DA LAI NAS CAPITAIS}

\begin{tabular}{|c|c|}
\hline CAPITAIS & REGULAMENTAÇÃO \\
\hline Aracaju & Decreto $^{\circ} 5.360 / 2016$ \\
\hline Belém & Decreto $\mathrm{n}^{\circ} 83.857 / 2015$ \\
\hline Belo Horizonte & $\begin{array}{l}\text { Decreto } n^{\circ} 14.906 / 2012 \text { alterado pelos Decreto } n^{\circ} 14.966 / 2012 \text {, Decreto } n^{\circ} \\
16.134 / 2015 \text { e Decreto } n^{\circ} 17.049 / 2019^{17}\end{array}$ \\
\hline Boa Vista & Decreto $^{\circ} 204 / 2013$ \\
\hline Campo Grande & Decreto $^{\circ}$ 13.2014/2017 revogou Decreto $n^{\circ} 11.842 / 2012$ \\
\hline Cuiabá & $\begin{array}{c}\text { Lei } \mathrm{n}^{\circ} 5.715 / 2013 \\
\text { Decreto } \mathrm{n}^{\circ} 5.477 / 2014\end{array}$ \\
\hline Curitiba & Decreto $\mathrm{n}^{\circ} 1.135 / 2012$ \\
\hline Florianópolis & Decreto $\mathrm{n}^{\circ} 9.988 / 2012$ \\
\hline Fortaleza & Decreto $n^{\circ} 13.305 / 2014$ \\
\hline Goiânia & Lei $\mathrm{n}^{\circ} 9.262 / 2013$ alterada pela Lei $\mathrm{n}^{\circ} 9.923 / 2016$ \\
\hline João Pessoa & Lei $\mathrm{n}^{\circ} 12.645 / 2013$ \\
\hline Macapá & Lei $n^{\circ} 2.265 / 2017$ \\
\hline Maceió & Decreto $n^{\circ} 8.052 / 2015$ \\
\hline Manaus & Decreto $^{\circ}{ }^{4} .157 / 2018$ revogou Decreto $\mathrm{n}^{\circ} 1.882 / 2012$ \\
\hline Natal & Decreto $^{\circ}{ }^{0} 11.264 / 2017$ revogou Decreto $n^{\circ} 10.087 / 2013$ \\
\hline Palmas & Decreto $n^{\circ} 462 / 2013$ \\
\hline Porto Alegre & Decreto $^{\circ}$ 19.990/2018 revogou Decreto $n^{\circ} 18.302 / 2013$ \\
\hline Porto Velho & Decreto $\mathrm{n}^{\circ} 14.565 / 2017$ revogou Decreto $\mathrm{n}^{\circ} 13.974 / 2015$ \\
\hline Recife & $\begin{array}{c}\text { Lei }^{\circ}{ }^{\circ} 17.866 / 2013 \\
\text { Decreto } n^{\circ} 28.527 / 2015\end{array}$ \\
\hline
\end{tabular}

17 Esta última alteração ocorreu após o levantamento normativo, mas foi noticiado pelo responsável da Prefeitura de Belo Horizonte, e sua análise foi incluída na pesquisa.

Rev. Controle, Fortaleza, v.19, n.2, p. 66-96, jul./dez. 2021. 


\begin{tabular}{|c|c|}
\hline Rio Branco & $\begin{array}{l}\text { Lei } \mathrm{n}^{\circ} 1.915 / 2012 \text { alterada pela Lei } \mathrm{n}^{\circ} 1.988 / 2013 \\
\text { Decreto } \mathrm{n}^{\circ} 3.556 / 2012 \text { alterado pelo Decreto } \mathrm{n}^{\circ} 1.455 / 2013\end{array}$ \\
\hline Rio de Janeiro & $\begin{array}{l}\text { Decreto }^{\circ} 44.745 / 2018 \text { revogou Decreto } n^{\circ} 42.671 / 2016 \text { e Decreto }{ }^{\circ} \\
35.793 / 2012\end{array}$ \\
\hline Salvador & 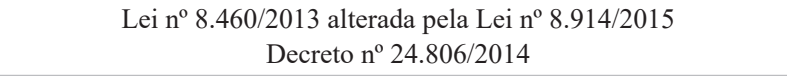 \\
\hline São Luís & Decreto $\mathrm{n}^{\circ} 47.272 / 2015$ \\
\hline São Paulo & $\begin{array}{c}\text { Decreto } \mathrm{n}^{\mathrm{o}} 53.623 / 2012 \text { alterado pelo Decreto } \mathrm{n}^{\circ} 54.779 / 2014 \\
\text { Resolução } \mathrm{n}^{\mathrm{o}} 01 / 2014\end{array}$ \\
\hline Teresina & Decreto $^{\circ} 14.605 / 2014$ \\
\hline Vitória & $\begin{array}{c}\text { Lei }^{\circ}{ }^{\circ} 8286 / 2012 \\
\text { Decreto } n^{\circ} 15.520 / 2012\end{array}$ \\
\hline
\end{tabular}

Fonte: Elaborado pelos autores, 2021. 